\title{
Calcium pyrophosphate crystal deposition disease: diagnosis and treatment
}

This article was published in the following Dove Press journal:

Open Access Rheumatology: Research and Reviews

8 May 2014

Number of times this article has been viewed

José Luis Rosales-

Alexander'

Jerónimo Balsalobre Aznar'

César Magro-Checa ${ }^{2}$

'Rheumatology Department, Hospiten Ramblas, Santa Cruz de Tenerife, ${ }^{2}$ Rheumatology Department, San Cecilio University Hospital, Granada, Spain
Correspondence: José Luis Rosales-Alexander Hospiten Ramblas, Rheumatology Department, Rambla Santa Cruz II5, 3800I, Santa Cruz de Tenerife, Spain Tel +34922534240

Email jose_rosales37@hotmail.com
Abstract: Calcium pyrophosphate dihydrate crystal deposition disease (CPPD) is an inflammatory arthritis produced by the deposition of calcium pyrophosphate (CPP) crystals in the synovium and periarticular soft tissues. It is the third most common inflammatory arthritis. Diagnosis is suspected on the basis of the clinical picture and radiographic/laboratory findings. The reference standard for the diagnosis of CPPD is based on the identification of CPP crystals in synovial fluid by light microscopy, compensated polarized light microscopy, or phase contrast microscopy. Most treatment approaches for CPPD are based upon clinical experience and not upon controlled trials. They range - depending on the subtype and the characteristics of symptoms - from no treatment to interleukin-1 blockade antibodies or specific therapy for an underlying disease. This review summarizes all we know so far about the diagnosis and management of CPPD.

Keywords: calcium pyrophosphate dihydrate deposition disease, CPPD, chondrocalcinosis, crystal-induced arthritides

\section{Introduction}

Calcium pyrophosphate (CPP) crystal deposits in articular tissues (mainly fibrocartilage and hyaline cartilage) and in periarticular soft tissues. ${ }^{1,2}$ Calcium pyrophosphate dihydrate crystal deposition disease (CPPD) may be asymptomatic or be associated with several clinical syndromes including both, acute and chronic inflammatory arthritis. ${ }^{3}$ The European League Against Rheumatism (EULAR) has suggested changes in CPPD terminology. ${ }^{2}$

According to the EULAR suggestions for CPPD terminology, CPPD has been proposed as the key term to include several disease phenotypes that include: the asymptomatic CPPD; the acute CPP crystal arthritis (previously known as pseudogout); osteoarthritis (OA) with CPPD (previously, pseudo-OA); and the chronic CPP crystal inflammatory arthritis (previously, pseudorheumatoid arthritis). ${ }^{2}$ In the same way, chondrocalcinosis (CC) has been proposed as the calcification of the cartilage identified by imaging or histological means. Although $\mathrm{CC}$ is most commonly due to CPP crystals, it is not exclusive of this disease and could appear as a casual finding or coexist with structural changes that resemble OA. ${ }^{2}$

In clinical practice, this disease may present as several phenotypes. In the asymptomatic CPPD, CC is a common finding in radiographic studies performed for any other reason, but it produces no symptoms. ${ }^{3}$ Acute CPP crystal arthritis should be suspected in a patient $>65$ years old. It presents typically as an acute monoarticular or oligoarticular arthritis, ${ }^{4}$ although migratory or additive arthritis and polyarticular and bilateral arthritis can also be a form of presentation. Large joints are frequently involved (knees, wrists, 
ankles), but it can affect any other joint. It has an abrupt onset and is characterized by pain, warmth, swelling, and - in some occasions - periarticular erythema. ${ }^{5}$

It is self-limiting and typically last 7-10 days. Attacks are typically triggered by intercurrent medical or surgical conditions between other factors. Generally, patients are asymptomatic between acute episodes. Attacks can affect the same joint or a different one in each episode. In some occasions, CPP crystal arthritis can present as an acute monoarthritis that affects a large joint and produces systemic symptoms such as fever, chills, and malaise; thus, septic arthritis must be always ruled out. ${ }^{4,5}$ Despite differences in joint involvement patterns between gout and CPP crystal arthritis, nowadays definite diagnosis relies upon the demonstration of the specific crystal in the synovial fluid (SF) of the inflamed joint. ${ }^{1,4}$

Chronic CPP crystal inflammatory arthritis may present as a chronic, bilateral, symmetrical, and deforming inflammatory polyarthritis. ${ }^{1}$ It frequently affects wrists and metacarpophalangeal joints, although tendon sheaths can also be affected. ${ }^{3}$ It may produce wrist tenosynovitis manifested as carpal tunnel syndrome and/or cubital tunnel syndrome. Radiographic findings are characterized by $\mathrm{CC}$, subchondral sclerosis, epiphyseal geodes, osteophytes, but with no marginal erosions. ${ }^{4}$

Differentiating chronic CPP crystal arthritis from rheumatoid arthritis (RA) can be challenging based upon clinical signs and symptoms; however, radiographic studies may help in this regard. Although CC is not exclusive of CPPD, it is not a common finding in RA; besides, the other radiographic signs mentioned for chronic CPP crystal arthritis may direct to a microcrystalline arthritis diagnosis. In other cases, when proximal joints of limbs are affected, it may be confused with rheumatic polymyalgia as well. ${ }^{1,4,5}$ A typical presentation - OA with CPPD — generally affects knees, has an atypical distribution (radiocarpal, glenohumeral, hindfoot, or midfoot involvement) and may be associated with more inflammatory signs and symptoms. ${ }^{4,5}$

At this point, an accurate diagnosis could be achieved on the basis of the clinical picture supported by several techniques. It is important to recognize the disease's subtypes, because treatment is not the same for all cases. So, this review summarizes what we know so far about diagnosis and management in CPPD.

\section{Diagnosis}

\section{SF}

Until a few years ago, CPPD diagnosis was based upon at least one of the following two conditions: 1) the demonstration of CPP crystals in SF or tissue by definitive methods, such as X-ray diffraction powder pattern, chemical analysis, or atomic force microscopy; and 2) by the identification of the CPP crystals in SF or tissue by compensated polarized light microscopy and the presence of CC on X-ray examination. ${ }^{1,4-6}$

Swan et $\mathrm{al}^{7}$ analyzed five studies, including a total of 35 laboratories, to assess the value of SF in the diagnosis of CPPD. They found that the identification of CPP crystals was worse than for monosodium urate monohydrate. A great variability between laboratories and readers in the identification of CPP crystals was disclosed. The authors concluded that further investigations were necessary to assess the real diagnostic value of the SF assay. ${ }^{7}$

Lumbreras et $\mathrm{al}^{8}$ assessed the reliability of CPP crystal identification. Trainees with no experience in crystal identification, after a 3-month course, blindly and independently examined SF samples that had been previously classified by an expert. They found that sensitivity and specificity for crystal detection (presence or absence of crystals) were $95.9 \%$ and $86.5 \%$, respectively. In the same way, sensitivity and specificity for CPP crystal identification were $92.7 \%$ and 92.1\%; trained observer reliability was very high. ${ }^{8}$

Nowadays, the identification of CPP crystals in SF by light microscopy, compensated polarized light microscopy, or phase contrast microscopy has become the reference standard for CPPD diagnosis. ${ }^{2}$ CPP crystals have characteristically a parallelepipedic form and are predominantly intracellular with absent or weak positive birefringence ${ }^{1-4}$ (Figure 1).

\section{X-ray}

Finding $\mathrm{CC}$ by radiographic means strengthens a CPPD diagnosis, but its absence does not rule it out. ${ }^{2}$ It is not infrequent to have positive detection of CPP crystals in SF analysis in patients with a negative X-ray. ${ }^{9-11}$ CPP crystal deposits in the fibrocartilage of the joints (most commonly in the menisci of

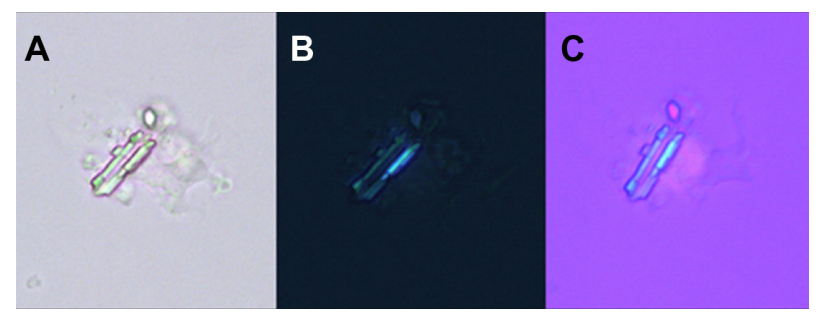

Figure I CPP crystal in SF.

Notes: (A) Parallelepipedic CPP crystals in SF by light microscopy. (B) CPP crystal by phase contrast microscopy. (C) CPP crystal showing weakly positive birefringence in compensated polarized light microscopy. All images had a 400x increase. Abbreviations: CPP, calcium pyrophosphate; SF, synovial fluid. 
the knee, triangular fibrocartilage of the wrists, labra of the acetabulum, symphysis pubis, and annulus fibrosus of the intervertebral disks). ${ }^{12}$ Calcification of hyaline cartilage occurs mainly in the wrist, knee, elbow, and hip. ${ }^{12}$ Synovial calcification is almost always seen in knee, metacarpophalangeal, metatarsophalangeal joints, radiocarpal, and distal radioulnar joints of the wrists. ${ }^{13}$ Tendon calcifications are frequently seen in the quadriceps, triceps, and Achilles tendon ${ }^{14}$ (Figure 2).

Abhishek et $\mathrm{al}^{15}$ demonstrated that almost $40 \%$ of individuals with $\mathrm{CC}$ do not present with $\mathrm{CPP}$ calcific radiographic findings on knees, despite being the most common site of CPPD involvement. They found that only $80 \%$ of these individuals with $\mathrm{CC}$ could be identified if the radiographs of knees and pelvis or knees and wrists/hands were performed. ${ }^{15}$ For that reason, a group of experts recommended assessing those sites to achieve an accurate diagnosis of radiographic CC..$^{15,16}$

\section{Ultrasonography (US)}

According to EULAR recommendations, US can demonstrate CPP crystals in peripheral joints, appearing typically as thin hyperechoic bands within hyaline cartilage and hyperechoic sparkling spots in fibrocartilage ${ }^{2}$ (Figure 3 ). An Italian expert group performed a case-control study to assess the utility of US in the diagnosis of CPPD. ${ }^{17}$ They found that CPP crystals were present in SF of all patients with CPP deposits defined by US. In only two patients, X-ray examinations not confirm the calcific deposits previously identified by US. The authors concluded that US patterns used in the study (as mentioned earlier in this paragraph) had a very high correlation with the presence of CPP crystals in SF and suggested that US may have at least an equal sensitivity and specificity to that of X-ray plain film in identifying CPP crystal calcifications. ${ }^{17}$ Moreover, a longitudinal study enrolled patients with ultrasonographic signs of CC, according to previously proposed criteria and

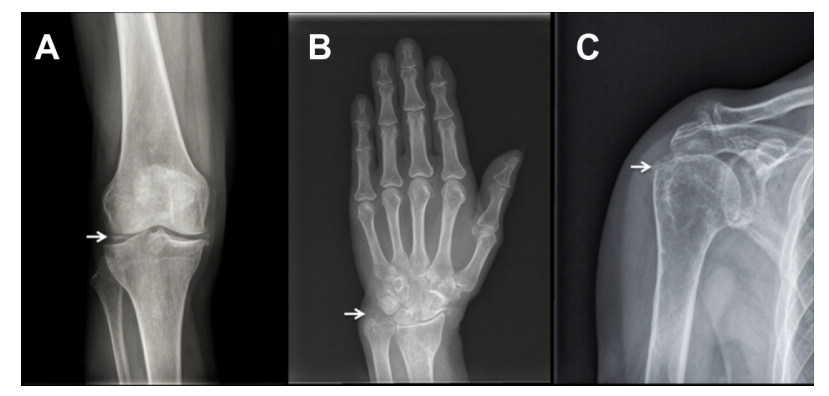

Figure 2 Radiographic CC.

Notes: (A) Plain film X-ray demonstrating CC involving the menisci (white arrow) (B) Disc of the triangular fibrocartilage complex of the wrist (white arrow). (C) Supraspinatus tendon calcification of the humerus (white arrows).

Abbreviation: CC, chondocalcinosis.

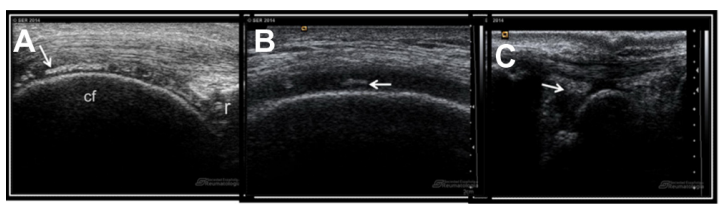

Figure 3 US findings of CPP crystals.

Notes: (A) US longitudinal scan demonstrates a hyperechoic band (white arrow) within hyaline cartilage of knee. (B) US transversal scan showing thin hyperechoic band within middle layer of hyaline cartilage of knee (white arrow). (C) US longitudinal scan of lateral dorsum of wrist that demonstrates hyperechoic band of carpal triangular ligament (white arrow).

Abbreviations: CPP, calcium pyrophosphate; US, ultrasonography; cf, femoral condyle; $r$, patella.

performed SF analysis and compared them with controls. Of the 14 patients classified as CC by US, 13 presented with CPP crystals in SF; whereas, only two of the 29 patients in the control group had CPP crystals after SF analysis. The authors concluded that US had a high specificity (96.4\%) and good sensitivity (86.7\%) for the diagnosis of CC, considering that CPP crystals could also be found in SF, even when the characteristic calcifications are not found in joint tissues by traditional radiology (sensitivity of $86.7 \%$ ). ${ }^{18}$

\section{Computed tomography}

CPPD may only affect the spine, but its involvement is often asymptomatic. ${ }^{19} \mathrm{CPP}$ crystals may deposit in the transverse ligaments of the atlas and in the alar ligaments, producing the so-called "crowned dens syndrome", which includes calcifications of all odontoid articular structures. ${ }^{20,21}$ In crowned dens syndrome, computed tomography is the gold standard imaging modality that allows identification of the different radiographic patterns of the disease: simple band of calcification or double band of thin calcifications in the transverse ligament; irregular calcifications crowning the dens apex; and bone erosions of the dens itself..$^{22,23}$

\section{Magnetic resonance imaging (MRI)}

There is not enough evidence to support the use of MRI in the evaluation of patients with suspected CPPD. ${ }^{14}$ Therefore, plain X-ray film has shown greater sensitivity than MRI in the diagnosis of CPP arthropathy of the knee. ${ }^{24}$ CPP crystals may be deposited in both ligamentum flavum and posterior longitudinal ligament, leading to myelopathy, cord compression, and spinal stenosis..$^{20,21}$ Thus, MRI may play a role in assessing rare complications of CPPD. ${ }^{14,25}$

\section{Management}

Optimal treatment requires both nonpharmacological and pharmacological therapies, according to clinical features and risks factors. ${ }^{26}$ Asymptomatic CPPD needs no treatment. ${ }^{4}$ 
Moreover, in other disease phenotypes, proper treatment should include prompt resolution of the acute synovitis, reduction of chronic joint damage, and management of associated conditions. ${ }^{5}$ Unfortunately, most treatment approaches are based upon clinical experience and not upon controlled trials. ${ }^{26}$

In acute attacks, therapeutic modalities used in gout are often required; however, evidence to support them in acute CPP crystal arthritis has yet to be systematically evaluated. ${ }^{27}$ In these cases, duration of attacks may be limited with cool packs, temporary rest, and joint aspiration combined with intra-articular long-acting glucocorticosteroids (GCS) injection. ${ }^{6,28}$ NSAIDs and low-dose oral colchicine (COL) are effective treatments but limited by toxicity and comorbidity, especially in older patients. A short course of oral or parenteral GCS may be effective for those patients in whom an intra-articular GCS injection or the use of NSAIDs and COL is not recommended. ${ }^{28}$

For the prophylaxis of recurrent acute CPP crystal arthritis, low-dose oral NSAIDs or low-dose oral COL $0.5-1.0 \mathrm{mg}$ daily may be used. ${ }^{6}$

Patients with chronic CPP crystal inflammatory arthritis sometimes require a continuous therapy; NSAIDS, COL, and low-dose oral GCS are frequently used with generally good results. However, occasionally these interventions are ineffective, contraindicated, or not well-tolerated and, for those situations, methotrexate (MTX) and hydroxychloroquine (HCQ) have shown to be good options (Table 1)..$^{6,28}$

\section{Nonsteroidal anti-inflammatory drugs (NSAIDs)}

The efficacy of these drugs in the treatment of CPPD has not been systematically evaluated. Furthermore, most of the

Table I CPPD management

\begin{tabular}{|c|c|c|}
\hline Disea & $\begin{array}{l}\text { Recommended } \\
\text { treatment }\end{array}$ & $\begin{array}{l}\text { Alternative } \\
\text { treatment }\end{array}$ \\
\hline $\begin{array}{l}\text { Asymptomatic CPPD } \\
\text { Acute CPP crystal } \\
\text { arthritis }\end{array}$ & $\begin{array}{l}\text { No treatment needed } \\
\text { Ice/cool packs } \\
\text { Relative rest } \\
\text { Joint drainage } \\
\text { Intra-articular long-acting } \\
\text { GCS injection } \\
\text { NSAIDs and/or low-dose } \\
\text { oral COL }\end{array}$ & $\begin{array}{l}\text { Short course of } \\
\text { oral GCS } \\
\text { Parenteral GCS } \\
\text { or ACTH }\end{array}$ \\
\hline $\begin{array}{l}\text { Osteoarthritis with } \\
\text { CPPD }\end{array}$ & $\begin{array}{l}\text { The same as for OA } \\
\text { without CPPD }\end{array}$ & \\
\hline $\begin{array}{l}\text { Chronic CPP crystal } \\
\text { inflammatory arthritis }\end{array}$ & $\begin{array}{l}\text { NSAIDS, low-dose oral } \\
\text { COL, low-dose oral GCS }\end{array}$ & $\begin{array}{l}\text { MTX and HCQ } \\
\text { ANK }\end{array}$ \\
\hline
\end{tabular}

Abbreviations: CPP, calcium pyrophosphate; CPPD, CPP deposition disease; GCS, glucocorticosteroids; ACTH, adrenocorticotrophic hormone; OA, osteoarthritis; NSAIDs, nonsteroidal anti-inflammatory drugs; COL, colchicine; MTX, methotrexate; HCQ, hydroxychloroquine; ANK, anakinra. information concerning this topic has been extrapolated from gouty arthritis studies. ${ }^{28,29}$ Although NSAIDs have not been critically compared and their choice remains empirical, all of these drugs seem to be effective. Furthermore, it has been recommended that full doses of selected drugs should be used as soon as possible. If a NSAID would pose an elevated risk to an individual (usually older patients) because of potential side effects, an alternative drug should be used. ${ }^{29}$

\section{GCS}

GCS are widely used in CPPD. One of the reasons is that CPPD arthritis predominates in older patients in whom the use of NSAIDs and COL is frequently contraindicated. Intra-articular GCS can be particularly useful in the treatment of acute monoarticular or oligoarticular episodes. A GCS, even if injected in small doses, is generally effective. ${ }^{28,29}$ Although infrequent, acute CPP crystal arthritis may coincide with septic arthritis. This possibility must be kept in mind, and GCS should not be used until infection has been ruled out. ${ }^{30}$

Oral and parenteral GCS preparations and adrenocorticotropic hormone $(\mathrm{ACTH})$ are useful alternatives for polyarticular cases in which a prompt response is needed or when COL and/or NSAIDs are contraindicated. ${ }^{30-32}$

A small noncontrolled trial that enrolled 27 patients with acute CPP crystal arthritis compared the efficacy of intramuscular betamethasone (7 mg), intravenous (IV) methylprednisolone (125 mg), and oral diclofenac $150 \mathrm{mg}$ per day during 3 days and then 3 extra days using one-half of the initial dose. They concluded that GCS may be more effective at gaining quick control of severe pain than NSAIDs. Few relapses were noted for all regimens, but there were no differences between IV and intramuscular GCS injections. ${ }^{30}$

Another uncontrolled trial described the results of 14 CPPD patients (12 of them were contraindicated to NSAIDs) receiving one or two intramuscular injections of triamcinolone acetonide. All of them had at least 50\% clinical improvement on visual analogue scale (VAS) within 14 days, without considerable side effects. In most patients, major clinical improvement occurred on the third and fourth day after the injection; however, a second injection was needed in six patients to control symptoms. ${ }^{31}$

Parenteral ACTH was used in a retrospective cohort study that included 38 patients with acute crystal arthritis (only five patients with CPPD). The indication for using ACTH included congestive heart failure, renal insufficiency, gastrointestinal bleeding, or resistance to NSAIDs. A total of 43 acute attacks were treated with IV ACTH, 40 or 80 units; all 
resolved within 4 days. Cases of mild hypokalemia, hyperglycemia, fluid retention, and rebound arthritis were reported and easily controlled. ${ }^{32}$

No data for low-dose GCS has been found as a treatment for chronic CPPD arthritis, and the EULAR recommendation about this is just supported by expert opinion. ${ }^{28}$ The use of different oral regimes of GCS in this disease has not been compared. ${ }^{30,31}$ We use prednisone $30 \mathrm{mg} /$ day with progressive dose reduction within a few days, according to clinical response; to avoid a rebound attack after the discontinuation of GCS, we start concomitantly COL at low doses.

Intra-articular dexamethasone stimulates CPP crystal formation by chondrocytes suggesting a potential detrimental effect of intra-articular GCS injections on articular cartilage. ${ }^{33}$ However, we would not recommend removing GCS from the already limited therapeutic armamentarium for CPPD.

\section{COL}

Although COL is one of the oldest drugs currently available, its mechanism of action, surprisingly, is not yet completely understood. ${ }^{34}$ The complex actions of this substance were initially thought to be mainly attributable to its stabilizing action on the cytoskeleton and cell membranes. ${ }^{35,36}$ Apart from that, COL also inhibits the neutrophil's motility and activity, leading to an anti-inflammatory effect.

Trial evidence supports its efficacy in acute CPP crystal arthritis and in preventing CPPD recurring attacks. ${ }^{37}$ As in acute gout, COL is most likely to be effective if treatment is started within 12-24 hours of symptom onset. The earlier the treatment is started - preferably within a few hours after the beginning of the attack - the more rapid and complete resolution of symptoms occurs. The duration of therapy for the acute episode may range from just a few days to several weeks, depending on how early or how late COL has been introduced in the treatment. ${ }^{36,37}$ In our experience, incipient CPP crystal attacks can be aborted with oral COL taken at the onset of symptoms ("pills in the pocket"). On the other hand, if other options are not contraindicated, we usually avoid the use of COL for acute CPP crystal arthritis that has been ongoing for more than 3-4 days because of the diminished likelihood of benefit.

In acute attacks, we prefer to start with smaller doses than those historically used. Such an approach in acute gout has been demonstrated to induce less diarrhea and abdominal cramping. ${ }^{35,36}$ It was customary to administer COL in the following manner: 1) $0.5 \mathrm{mg}$ every hour; or 2) $1 \mathrm{mg}$ every 2 hours until the pain was relieved, or the gastrointestinal symptoms supervened. With such high doses, the incidence of marked side effects was almost $100 \% .{ }^{37-39}$ We prefer to use an alternative low-dose COL regimen that is $0.6 \mathrm{mg}$ (or $0.5 \mathrm{mg}$ available in other countries other than the US) three times per day on the first days of treatment. In most patients, the effect of this oral therapy is dramatic; joint symptoms usually begin to subside in 12-24 hours, and the attack has abated, if treated early, in 72 hours, with fewer toxic effects.

The IV administration of COL is avoided, due to the risk of severe pancytopenia and death - although one uncontrolled hospital case series showed the efficacy of IV COL in seven patients with acute attacks. ${ }^{40}$

The effectiveness of COL as a prophylactic agent in recurring CPP crystal arthritis was shown in a study ${ }^{39}$ in which 10 patients with recurrent arthritis attacks were started on this drug (oral COL $0.6 \mathrm{mg}$, two times daily) and followed for 1 year after receiving the therapy. Acute episodes of arthritis were diminished from 3.2 patients/year to one patient/year ( $90 \%$ of the patients benefitted from COL use). ${ }^{39}$

\section{$\mathrm{HCQ}$}

In a prospective 6-month, double-blinded trial, HCQ was suggested to be of some benefit in chronic CPP crystal inflammatory arthritis. In addition, 36 patients were investigated. The number needed to treat for clinical response was 2 (95\% confidence interval 1-7). Clinical response rate was defined as the percentage of patients with more than $30 \%$ reduction of tender and swollen joints. There were no significant side effects. ${ }^{41}$

\section{MTX}

MTX could be considered as an alternative therapeutic option for patients with severe CPPD who failed to respond to standard therapy. ${ }^{28}$ It works not only as an immunosuppressant but also as a potent anti-inflammatory agent.

In a study that included five patients treated with low dosages of MTX (5-20 mg/week), all patients reported an excellent clinical response, with marked improvement within a mean period of 7.4 weeks. The frequency of CPP crystal arthritis attacks, pain intensity, the number of swollen and tender joints, and inflammatory biomarkers were all improved after the initiation of MTX therapy. No significant side effects were reported. ${ }^{42}$

In another observational study in which ten patients were included, the authors concluded that MTX could be an effective and safe option for patients with refractory CPPD arthritis. Also, five patients presented with a persistent polyarthritis, while three presented with a persistent oligoarthritis, and 
two presented with a relapsing monoarthritis. Median MTX evaluation by patients on a visual analog scale was 7.4; physicians considered the response to the drug: excellent $(n=2)$; $\operatorname{good}(n=5)$; or medium $(n=3) .{ }^{43}$

\section{Anakinra (ANK)}

Interleukin $1 \beta$ (IL-1 $\beta$ ) plays a central role in crystal-induced inflammation. At this respect, pyrophosphate crystals act via the NALP3 inflammasome to convert prointerleukin-1 into IL- $1 .{ }^{44}$

Traditional anti-inflammatory agents may act on the IL-1 $\beta$ pathway at some level; however, their mechanisms of action are broad-ranging, unspecific, and biologically complex. This lack of specificity may explain the range of systemic adverse effects associated with them. ${ }^{45}$ The therapeutic margins of NSAIDs, COL, and GCS are particularly low in elderly patients and in patients with cardiovascular, metabolic, or renal comorbidities. Concerning this, IL-1 $\beta$ antagonists target an early event immediately downstream from NALP3 inflammasome activation, thus reducing systemic adverse events and providing an effective alternative treatment compared to traditional agents. ${ }^{45-48}$

ANK blocks the biologic activity of IL-1 alpha and beta by competitively inhibiting IL-1 binding to the IL-1 type I receptor (IL-1RI), which is expressed in a wide variety of tissues and organs. ${ }^{45}$

A case of a 71-year-old man with recurrent CPP crystal arthritis and end-stage renal failure that contraindicated treatment with COL or NSAIDs and resistant to GCS therapy was reported to respond to this therapy after a follow-up of 8 months. ANK was administered as preventive therapy 3 days per week after each hemodialysis session. ${ }^{46}$

A recurrent knee oligoarthritis with short effect response to GCS was treated with ANK showing a rapid improvement (within 1 week) of inflammation. However, patients were unable to withdrawal from treatment in the long term, due to recurrent attacks. ${ }^{47}$

\section{Magnesium (MG)}

In vitro studies have shown that $\mathrm{MG}$ can solubilize CPP crystals and has inhibitory effects on the nucleation and growth of these crystals. ${ }^{49}$ The possibility that MG supplementation might influence CPP crystals in vivo is suggested by the reduction of acute CPP crystal arthritis after lavage of joints with MG sulphate ${ }^{50}$ and by a possible reported benefit of $\mathrm{MG}$ replacement treatment in a patient with hypomagnesaemia and CC. ${ }^{51}$ One small double-blind, placebo-controlled RCT was undertaken in 38 patients with symptomatic knee
OA with CPPD. Despite a pronounced placebo effect in controls, the treatment showed a uniform trend toward improvement in pain, stiffness, joint line tenderness, effusion (knee), and overall subjective and objective assessment. There was no reduction in radiographic CC in those receiving magnesium compared with those given placebo. ${ }^{52}$

\section{Radiosynovectomy}

In one small double-blinded study, 15 patients with bilateral, symmetrical, CPPD arthropathy of the knees were given intraarticular injections of yttrium-90 (5 mCi) plus steroid (triamcinolone hexacetonide, $20 \mathrm{mg}$ ) into one knee, and saline plus steroid into the other knee (control). After 6 months, there was significantly less pain, inactivity stiffness, joint-line tenderness, and effusion in the 90 Y-injected knees than in the controls. There were also significant differences in the range of movement and joint circumference caused partly by progression of disease in the control knees. In all cases, patient and observer assessment favored the treated knee. ${ }^{53}$

According to EULAR recommendations, this therapy should be considered in older patients with CPPD arthropathy and recurrent hemarthrosis affecting the shoulder, though in the absence of any supporting trial. ${ }^{28}$

\section{Hyaluronan}

An amelioration of pain and range of movement was observed after the injection of $2 \mathrm{~mL}$ of sodium hyaluronate (HYALGAN $^{\circledR}$, Fidia Farmaceutici SpA, Abano Terme, Italy) once a week during 4 weeks in patients where the treatment with NSAIDs and SF drainage was ineffective. No adverse events were observed after the injections in those patients. ${ }^{54}$ Similar results were obtained by other authors in patients with radiologic $\mathrm{CC}$ with knee OA:55,56 however, in some cases, the development of acute synovitis has been described after hyaluronic acid injections, ${ }^{57}$ this therapy is recommended in the American College of Rheumatology guidelines for OA treatment. ${ }^{58}$

\section{Others}

High inorganic pyrophosphate levels appear central to CPP crystal formation. There is considerable interest, but no relevant data, on the possibility of using pharmacological agents, such as probenecid, polyphosphates, and phosphocitrate to modulate pyrophosphate levels and to influence CPP crystal formation and dissolution. ${ }^{59-61}$ At present, this remains only a theoretical possibility that needs to be further confirmed.

In CPPD, there is an excess of extracellular inorganic pyrophosphate elaboration by chondrocytes. Transforming growth factor beta-1 is their main stimulant. Probenecid blocks 
transforming growth factor beta-1 induced pyrophosphate synthesis, suggesting a potential role to counteract this aberrant metabolism. ${ }^{59}$

Linear polyphosphates are effective in dissolving both synthetic and ex vivo CPP crystal aggregates. ${ }^{60}$ This suggests a potential therapeutic use for these molecules in the treatment of symptomatic CC.

It has been proposed that the binding of phosphocitrate to specific faces of CPP crystals induces morphological changes that may lead to diminished crystal growth or its total cessation. ${ }^{61}$

\section{Treatment for concurrent OA}

Calcium-containing crystals are quite common in primary OA and may worsen it through the induction of inflammation by neutrophils. COL inhibits monosodium urate monohydrate crystal- and CPP crystal-induced inflammation. Hence, it was hypothesized that COL may have symptom-modifying effects on OA. The efficacy and safety of COL for pain reduction in OA was confirmed by a double-blind randomized controlled trial where 61 postmenopausal patients with primary knee OA were enrolled. Interestingly, none of them had evidence of $\mathrm{CC}$ in radiographic studies. Improvement rate at the end of 3 months was significantly higher in the COL group for both the patient's global assessment and the physician's global assessment measures compared to placebo group. ${ }^{62}$

Another study was performed to evaluate the symptomatic benefit of the addition of COL to a regimen of intra-articular GCS. Thirty-nine patients with knee OA with persisting synovitis despite 2 weeks of piroxicam were subjected to intra-articular steroid injection and randomly assigned to receive COL $0.5 \mathrm{mg}$ twice daily or placebo. The authors found that the addition of COL produced significantly greater symptomatic benefit at the 16 th and 20 th weeks in patients with knee OA with inflammation. ${ }^{63}$

Concurrence of OA with CPPD might be associated with an increased inflammatory component and a different prognosis with respect to rate of clinical and radiographic progression, ${ }^{64-66}$ but the repertoire of treatments remains basically the same as that for OA. ${ }^{28}$ Future research agenda should analyze a possible disease-modifying effect of COL in concurrent $\mathrm{OA}$ with an inflammatory component due to CPPD arthritis.

\section{Treatment of comorbidities}

Therapy is symptom-oriented or disease-specific in the case of an underlying metabolic disease, such as hemochromatosis, hyperparathyroidism, hypophosphatasia, hypomagnesaemia, or hypothyroidism. ${ }^{28}$

If a disease associated with CPPD is present, specific therapy for the underlying disease should be initiated - even though this measure does not reverse crystal deposition. A case of reduced meniscal calcification was reported to happen over a 10-year course of oral magnesium administration in a patient with CPPD arthropathy and hypomagnesemia. ${ }^{66}$

Most patients continue to develop new calcifications despite successful treatment of the associated metabolic disorder. ${ }^{67-70}$ The case of hyperparathyroidism shows this fact. Patients with CPPD are three times more likely to have primary hyperparathyroidism than patients without CPPD (odds ratio $=3.03 ; 95 \%$ confidence interval $1.15-8.02){ }^{2}$ Conversely, patients with primary hyperparathyroidism may have an increased risk of acute attacks of CPPD arthritis. ${ }^{71,72}$ In such a predisposing condition, treatment is obviously required, though whether treatment of such comorbidity affects the outcome of CPPD-associated arthritis is unclear. In a retrospective study of 57 patients with primary hyperparathyroidism and an overall incidence of CC of $40 \%$, neither joint symptoms nor radiological CC regressed after surgery. ${ }^{71}$ These data have been also reported in another series of 41 patients in which parathyroidectomy had no effect on arthritis attacks or on preexisting cartilage calcification. ${ }^{72}$

Since a drug that can prevent the aberrant inorganic pyrophosphate metabolism does not exist, in these cases treatment is primarily symptomatic.

\section{Conclusion}

CPPD diagnosis is based on the identification of CPP crystals in microscopy. Treatment approaches are based upon clinical experience and are, in most cases, extrapolated from gouty arthritis. If CPPD is associated with an underlying disease, specific therapy should be started.

\section{Acknowledgments}

Photographs in Figure 3 are courtesy of the Image Bank of the Spanish Society of Rheumatology; with permission from Dra. Esperanza Naredo (A) and Eugenio de Miguel (B, C).

\section{Disclosure}

The authors report no conflicts of interest in this work.

\section{References}

1. Terkeltaub R. Diseases associated with articular deposition of calcium pyrophosphate dehydrate and basic calcium phosphate crystals. In: Firestein GS, Budd RC, Harris Jr ED, McInnes IB, Ruddy S, Sergent JS, editors. Kelley's Textbook of Rheumatology. 8th ed. Philadelphia: Elsevier Saunders; 2009:1507-1524. 
2. Zhang W, Doherty M, Bardin T, et al. European League Against Rheumatism recommendations for calcium pyrophosphate deposition. Part I: terminology and diagnosis. Ann Rheum Dis. 2011;70(4):563-570.

3. Ryan LM, McCarty DJ. Calcium pyrophosphate crystal deposition disease, pseudogout and articular chondrocalcinosis. In: Koopman WJ, editor. Arthritis and Allied Conditions: A Textbook of Rheumatology. 13th ed. Baltimore: Williams \& Wilkins; 1997:2103-2125.

4. Rosenthal AK, Ryan LM, McCarty DJ. Calcium pyrophosphate crystal deposition disease, pseudogout, and articular chondrocalcinosis. In: Arthritis and Allied Conditions, 15th, Koopman WJ, Moreland LW (Eds), Lippincott Williams \& Wilkins, Philadelphia, USA; 2005: 2373-2396.

5. Rosenthal AK. Pseudogout: Presentation, Natural History, and Associated Conditions. In: Wortmann RL, Schumacher HR Jr, Becker MA, Ryan LM, editors. Crystal-Induced Arthropathies: Gout, Pseudogout, and Apatite-Associated Syndromes. New York: Taylor \& Francis Group; 2006:99-116.

6. McCarty DJ. Calcium pyrophosphate dihydrate crystal deposition disease - 1975. Arthritis Rheum. 1976;19 Suppl 3:275-285.

7. Swan A, Amer H, Dieppe P. The value of synovial fluid assays in the diagnosis of joint disease: a literature survey. Ann Rheum Dis. 2002;61(6):493-498.

8. Lumbreras B, Pascual E, Frasquet J, González-Salinas J, Rodríguez E, Hernández-Aguado I. Analysis for crystals in synovial fluid: training of the analysts results in high consistency. Ann Rheum Dis. 2005;64(4): $612-615$.

9. Martínez Sanchis A, Pascual E. Intracellular and extracellular CPPD crystals are a regular feature in synovial fluid from uninflamed joints of patients with CPPD related arthropathy. Ann Rheum Dis. 2005;64(12):1769-1772.

10. Louthrenoo W, Sukitawut W. Calcium pyrophosphate dihydrate crystal deposition: a clinical and laboratory analysis of 91 Thai patients. J Med Assoc Thai. 1999;82(6):569-576.

11. Utsinger PD, Resnick D, Zvaifler NJ. Wrist arthropathy in calcium pyrophosphate dihydrate deposition disease. Arthritis Rheum. 1975;18(5): 485-491.

12. Paparo F, Fabbro E, Ferrero G, et al. Imaging studies of crystalline arthritides. Reumatismo. 2012;63(4):263-275.

13. Schumacher HR. Ultra structural findings in chondrocalcinosis and pseudogout. Arthritis Rheum. 1976;19 Suppl 3:413-425.

14. Steinbach LS. Calcium pyrophosphate dihydrate and calcium hydroxyapatite crystal deposition diseases: imaging perspectives. Radiol Clin North Am. 2004;42(1):185-205, vii.

15. Abhishek A, Doherty S, Maciewicz R, Muir K, Zhang W, Doherty M. Chondrocalcinosis frequently occurs at the wrists and hips in the absence of knee involvement. Ann Rheum Dis. 2013;71(Suppl 3):S442.

16. Filipou G, Frediani B. The diagnosis of calcium pyrophosphate dihydrate crystal deposition disease: the good, the bad and ... ultrasonography! Reumatismo. 2012;64(3):125-127.

17. Frediani B, Filippou G, Falsetti P, et al. Diagnosis of calcium pyrophosphate dihydrate crystal deposition disease: ultrasonographic criteria proposed. Ann Rheum Dis. 2005;64(4):638-640.

18. Filippou G, Frediani B, Gallo A, et al. A "new" technique for the diagnosis of chondrocalcinosis of the knee: sensitivity and specificity of high-frequency ultrasonography. Ann Rheum Dis. 2007;66(8): 1126-1128.

19. Constantin A, Marn F, Bon E, Fedele M, Lagarrigue B, Bouteiller G. Calcification of the transverse ligament of the atlas in chondrocalcinosis: computed tomography study. Ann Rheum Dis. 1996;55(2): 137-139.

20. Baysal T, Baysal O, Kutlu E, Karaman I, Mizrak B. The crowned dens syndrome: a rare form of calcium pyrophosphate deposition disease. Eur Radiol. 2000;10(6):1003-1005.

21. Aouba A, Vuillemin-Bodaghi V, Mutschler C, De Bandt M. Crowned dens syndrome misdiagnosed as polymyalgia rheumatica, giant cell arteritis, meningitis or spondylitis: an analysis of eight cases. Rheumatology (Oxford). 2004;43(12):1508-1512.
22. Sekijima Y, Yoshida T, Ikeda S. CPPD crystal deposition disease of the cervical spine: a common cause of acute neck pain encountered in the neurology department. J Neurol Sci. 2010;296(1-2):79-82.

23. Scutellari PN, Galeotti R, Leprotti S, Ridolfi M, Franciosi R, Antinolfi G. The crowned dens syndrome. Evaluation with CT imaging. Radiol Med. 2007;112(2):195-207. Italian [with English abstract].

24. Abreu M, Johnson K, Chung CB, et al. Calcification in calcium pyrophosphate dehydrate (CPPD) crystalline deposits in the knee: anatomic, radiographic, MR imaging, and histologic study in cadavers. Skeletal Radiol. 2004;33(7):392-398.

25. Fenoy AJ, Menezes AH, Donovan KA, Kralik SF. Calcium pyrophosphate dihydrate crystal deposition in the craniovertebral junction. J Neurosurg Spine. 2008;8(1):22-29.

26. Rosenthal AK, Ryan LM. Crystal arthritis: calcium pyrophosphate deposition-nothing 'pseudo' about it! Nat Rev Rheumatol. 2011;7(5): 257-258.

27. Martinon F, Pétrilli V, Mayor A, Tardivel A, Tschopp J. Goutassociated uric acid crystals activate the NALP3 inflammasome. Nature. 2006;440(7081):237-241.

28. Zhang W, Doherty M, Pascual E, et al. EULAR recommendations for calcium pyrophosphate deposition. Part II: management. Ann Rheum Dis. 2011;70(4):571-575.

29. Rosenthal AK. Update in calcium deposition diseases. Curr Opin Rheumatol. 2007;19(2):158-162.

30. Werlen D, Gabay C, Vischer TL. Corticosteroid therapy for the treatment of acute attacks of crystal-induced arthritis: an effective alternative to nonsteroidal antiinflammatory drugs. Rev Rhum Engl Ed. 1996;63(4):248-254.

31. Roane DW, Harris MD, Carpenter MT, et al. Prospective use of intramuscular triamcinolone acetonide in pseudogout. J Rheumatol. 1997;24(6):1168-1170.

32. Ritter K, Kerr LD, Valeriano-Marcet J, Spiera H. ACTH revisited: effective treatment for acute crystal induced synovitis in patients with multiple medical problems. J Rheumatol. 1994;21(4):696-699.

33. Fahey M, Mitton E, Muth E, Rosenthal AK. Dexamethasone promotes calcium pyrophosphate dihydrate crystal formation by articular condrocytes. J Rheumatol. 2009;36(1):163-169.

34. Choy G. An update on the treatment options for gout and calcium pyrophosphate deposition. Expert Opin Pharmacother. 2005;6(14): 2443-2453.

35. Lange U, Schumann C, Schmidt KL. Current aspects of colchicine therapy - classical indications and new therapeutic uses. Eur J Med Res. 2001;6(4):150-160.

36. Cocco G, Chu DC, Pandolfi S. Colchicine in clinical medicine. A guide for internists. Eur J Intern Med. 2010;21(6):503-508.

37. Niel E, Scherrmann JM. Colchicine today. Joint Bone Spine. 2006;73(6):672-678.

38. Molad Y. Update on colchicine and its mechanism of action. Curr Rheumatol Rep. 2002;4(3):252-256.

39. Tabatabai MR, Cummings NA. Intravenous colchicine in the treatment of acute pseudogout. Arthritis Rheum. 1980;23(3):370-374.

40. Alvarellos A, Spilberg I. Colchicine prophylaxis in pseudogout. J Rheumatol. 1986;13(4):804-805.

41. Rothschild B, Yakubov LE. Prospective 6-month, double-blind trial of hydroxychloroquine treatment of CPDD. Compr Ther. 1997;23(5): 327-331.

42. Chollet-Janin A, Finckh A, Dudler J, Guerne PA. Methotrexate as an alternative therapy for chronic calcium pyrophosphate deposition disease: an exploratory analysis. Arthritis Rheum. 2007;56(2): 688-692.

43. Andres M, Sivera F, Pascual E. Methotrexate is an option for patients with refractory calcium pyrophosphate crystal arthritis. J Clin Rheumatol. 2012;18(5):234-236.

44. Torres R, Macdonald L, Croll SD, et al. Hyperalgesia, synovitis and multiple biomarkers of inflammation are suppressed by interleukin 1 inhibition in a novel animal model of gouty arthritis. Ann Rheum Dis. 2009;68(10):1602-1608. 
45. Cronstein BN, Sunkureddi P. Mechanistic aspects of inflammation and clinical management of inflammation in acute gouty arthritis. J Clin Rheumatol. 2013;19(1):19-29.

46. Announ N, Palmer G, Guerne PA, Gabay C. Anakinra is a possible alternative in the treatment and prevention of acute attacks of pseudogout in end-stage renal failure. Joint Bone Spine. 2009;76(4):424-426.

47. Diamantopoulos AP, Brodin C, Hetland H, Haugeberg G. Interleukin $1 \beta$ blockade improves signs and symptoms of chronic calcium pyrophosphate crystal arthritis resistant to treatment. J Clin Rheumatol. 2012;18(6):310-311.

48. Dinarello CA, Simon A, van der Meer JW. Treating inflammation by blocking interleukin-1 in a broad spectrum of diseases. Nat Rev Drug Discov. 2012;11(8):633-652.

49. Cheng PT, Pritzker KP. The effect of calcium and magnesium ions on calcium pyrophosphate crystal formation in aqueous solutions. J Rheumatol. 1981;8(5):772-782.

50. Bennett RM, Lehr JR, McCarty DJ. Crystal shedding and acute pseudogout. An hypothesis based on a therapeutic failure. Arthritis Rheum. 1976;19(1):93-97.

51. Runeberg L, Collan Y, Jokinen EJ, Lähdevirta J, Aro A. Hypomagnesemia due to renal disease of unknown etiology. Am J Med. 1975;59(6):873-881.

52. Doherty M, Dieppe PA. Double blind, placebo controlled trial of magnesium carbonate in chronic pyrophosphate arthropathy. Ann Rheum Dis. 1983;42:106-110. Available from: http://ard.bmj.com/content/42/ Suppl_1/106.full.pdf\%20html. Accessed April 23, 2014.

53. Doherty M, Dieppe PA. Effect of intra-articular yttrium- 90 on chronic pyrophosphate arthropathy of the knee. Lancet. 1981;2(8258):1243-1246.

54. Punzi L, Ramonda R, Cavasin F, Schiavon F, Gambari PF, Todesco S. A preliminary report on the effect of intraarticular hyaluronic acid in chondrocalcinosis. 5th EULAR Symposium; November 10-12, 1988; Paris. Rev Rhum Mal Osteoartic. 1988;Oct 30;55 (10 Pt 2):808-884.

55. Daumen-Legre V, Pham T, Acquaviva PC, Lafforgue P. Evaluation of safety and efficacy of viscosupplementation in knee osteoarthritis with chondrocalcinosis. Arthritis and Rheumatism. 1999;42(9):S158.

56. Romera M. Effect of intraarticular hyaluronate injections in chondrocalcinosis: comment on the article by Martens. Arthritis Rheum. 2002;46(3):847.

57. Punzi L, Pianon M, Piero SG, Todesco S. Pseudogout and intraarticular hyaluronate injections: comment on the article by Disla et al. Arthritis Rheum. 2000;43(7):1660-1661.

58. Recommendations for the medical management of osteoarthritis of the hip and knee: 2000 update. American College of Rheumatology Subcommittee on Osteoarthritis Guidelines. Arthritis Rheum. 2000;43(9):1905-1915.
59. Trostle D, Schumacher HR. Probenecid therapy of refractory CPPD deposition disease. Arthritis and Rheumatism. 1999;42(9):S160.

60. Cini R, Chindamo D, Catenaccio M, et al. Dissolution of calcium pyrophosphate crystals by polyphosphates: an in vitro and ex vivo study. Ann Rheum Dis. 2001;60(10):962-967.

61. Cheung HS. Phosphocitrate as a potential therapeutic strategy for crystal deposition disease. Curr Rheumatol Rep. 2001;3(1):24-28.

62. Aran S, Malekzadeh S, Seifirad S. A double-blind randomized controlled trial appraising the symptom-modifying effects of colchicine on osteoarthritis of the knee. Clin Exp Rheumatol. 2001;29(3): 513-518.

63. Das SK, Mishra K, Ramakrishnan S, et al. A randomized controlled trial to evaluate the slow-acting symptom modifying effects of a regimen containing colchicine in a subset of patients with osteoarthritis of the knee. Osteoarthritis Cartilage. 2002;10(4):247-252.

64. Doherty M, Dieppe P, Watt I. Pyrophosphate arthropathy: a prospective study. Br J Rheumatol. 1993;32(3):189-196.

65. Ledingham J, Regan M, Jones A, Doherty M. Factors affecting radiographic progression of knee osteoarthritis. Ann Rheum Dis. 1995;54(1):53-58.

66. Smilde TJ, Haverman JF, Schipper P, et al. Familial hypokalemia/ hypomagnesemia and chondrocalcinosis. The Journal of Rheumatology. 1994;21(8):1515-1519.

67. Hamilton EB, Bomford AB, Laws JW, Williams R. The natural history of arthritis in idiopathic haemochromatosis: progression of the clinical and radiological features over ten years. $Q J$ Med. 1981;50(199): 321-329.

68. Van Geertruyden J, Kinnaert P, Frederic N, Fuss M, Corvilain J. Effect of parathyroid surgery on cartilage calcification. World J Surg. 1986;10(1):111-115.

69. Glass JS, Grahame R. Chondrocalcinosis after parathyroidectomy. Ann Rheum Dis. 1976;35(6):521-525.

70. Pritchard MH, Jessop JD. Chondrocalcinosis in primary hyperparathyroidism. Influence of age, metabolic bone disease, and parathyroidectomy. Ann Rheum Dis. 1977;36(2):146-151.

71. White JC, Brandt FB, Geelhoed GW. Acute pseudogout following parathyroidectomy. Am Surg. 1988;54(8):506-509.

72. Geelhoed GW, Kelly TR. Pseudogout as a clue and complication in primary hyperparathyroidism. Surgery. 1989;106(6):1036-1041, discussion 1041-1042.
Open Access Rheumatology Research and Reviews

\section{Publish your work in this journal}

Open Access Rheumatology Research and Reviews is an international, peer-reviewed, open access journal, publishing all aspects of clinical and experimental rheumatology in the clinic and laboratory including the following topics: Pathology, pathophysiology of rheumatological diseases; Investigation, treatment and management of rheumatological

\section{Dovepress}

diseases; Clinical trials and novel pharmacological approaches for the treatment of rheumatological disorders. The manuscript management system is completely online and includes a very quick and fair peerreview system, which is all easy to use. Visit http://www.dovepress.com/ testimonials.php to read real quotes from published authors. 